\title{
Oncologic Results of Breast Conserving Surgery under Procedural Sedation in Elderly Patients
}

\author{
Jeeyeon Lee, M.D., Ph.D., Jin Hyang Jung, M.D., Ph.D., Wan Wook Kim, M.D., Yang Soo Lim, M.D., \\ Ryu Kyung Lee, M.D., Kyung-Hwa Kwak ${ }^{1 \star}$, M.D., Ph.D., Ho Yong Park*, M.D., Ph.D. \\ Departments of Surgery, ${ }^{1}$ Anesthesiology and Pain Medicine, Kyungpook National University School of Medicine, Daegu, Korea
}

Purpose: Although surgery is the most frequently implemented treatment modality for breast cancer, many older patients with breast cancer are under- or untreated because of their high incidence of postoperative complications. We assessed the efficacy and safety of breast surgery under procedural sedation in older patients (aged $>70$ years) by comparing selected clinical and oncologic factors after surgery for breast cancer under general anesthesia versus procedural sedation. Methods: Of 79 older patients with breast cancer, 49 underwent breast-conserving surgery, 30 under general anesthesia and 19 under procedural sedation, and relevant clinical and oncologic variables were compared and analyzed between groups. Results: The mean age was younger in the general anesthesia group and the mean operation time, hospital stay, and fasting time shorter in the procedural sedation group. There were no statistically significant differences in oncologic results between the two groups during follow-up. Conclusion: Breast surgery under procedural sedation is a safe and effective means of reducing tumor burden in older patients with breast cancer when their American Society of Anesthesiologists (ASA) physical status indicates a high risk of life-threatening perioperative complications associated with general anesthesia. And we also found that the oncologic results may be not inferior to same procedure under general anesthesia.

Key Words: Aged, Breast neoplasms, Sedation, Surgery

\section{INTRODUCTION}

Average life expectancy has consistently been increasing worldwide, having reached over 70 years by 2015 [1]. This extension of life span has been associated with more rigorous health checks and an increasing incidence of early breast cancer in older patients $[2,3]$

In the past, elderly with breast cancer frequently underwent conservative treatment only for breast cancer. Although breast cancer grows

Correspondence: Ho Yong Park, M.D., Ph.D.

Department of Surgery, Kyungpook National University School of Medicine, 807 Hoguk-ro, Buk-gu, Daegu 41404, Korea

Tel: +82-53-200-2703, Fax: +82-53-200-2027, E-mail: phy123@knu.ac.kr

Correspondence: Kyung-Hwa Kwak, M.D., Ph.D.

Department of Anesthesiology and Pain Medicine, Kyungpook National University School of Medicine, 807 Hoguk-ro, Buk-gu, Daegu 41404, Korea Tel: +82-53-200-2166, Fax: +82-53-200-2027, E-mail: kwakkh@knu.ac.kr

*These authors contributed equally to this work.

This work was supported by the National Research Foundation of Korea (NRF) grant funded by the Korea government (2014R1A-5A2009242,

2017R1C1B5076186) and by a grant from the National R\&D Program for Cancer Control, Ministry of Health and Welfare, Republic of Korea (1420040). And this research was supported by a grant of the Korea Health Technology R\&D Project through the Korea Health Industry Development Institute (KHIDI), funded by the Ministry of Health \& Welfare, Republic of Korea (HI17C1142).

Received:Sep 5, 2018 Revised: Nov 5, 2018 Accepted: Jan 29, 2019 more slowly and has a better prognosis in elderly [4,5], many studies have suggested that they should be managed actively [6-10]. However, the comorbidities of elderly may hinder implementation of active forms of treatment.

The American Society of Anesthesiologists (ASA) Physical Status classification of surgical patients is a standard element of preoperative assessment [11]. Although this classification does not propose absolute criteria for suitability for general anesthesia, an individual's risk of postoperative complications or morbidities can be predicted because the presence and severity of comorbidities have been evaluated. When a patient has an extremely high risk of postoperative morbidity or mortality, the patient and their caregivers may refuse surgery under general anesthesia not because they believe that the surgery itself is too dangerous, but because they fear life-threatening postoperative complications of general anesthesia.

Surgical removal is the most important treatment for breast cancer regardless of whether other neoadjuvant or adjuvant treatments are administered [12,13]. Excision of breast cancers not only reduces tumor burden, thus maximizing the therapeutic effect, but also enables accurate assessment of tumor characteristics, which is important 
when considering adjuvant treatments. Removal of the main lesion is important as treatment of breast cancer that consideration should be given to performing it under procedural sedation in elderly who are at high risk of complications after general anesthesia. However, there is no remarkable oncologic result according to the anesthetic method which makes the type of surgery differently.

This study was conducted to assess the efficacy and safety of performing surgery for breast cancer under procedural sedation in older patients when general anesthesia is considered too risky.

\section{METHODS}

Data of 79 eligible patients with operable breast cancer who were older than 70 years and attended our institution between January
2011 and December 2016 were collected prospectively for this study. Of these, 49 patients underwent breast-conserving surgery under general $(n=30)$ or procedural sedation $(n=19)$. These patients' clinical and oncologic factors were compared and analyzed (Figure 1). The study protocol used was approved by Institutional Review Board at the Kyungpook National University Chilgok Hospital.

All breast cancers were confirmed by core needle or excision biopsy and their size, number and location assessed by mammography, ultrasonography, and breast magnetic resonance (MR) imaging. The axillary lymph node was negative in all patients based on imaging modalities. Patients with severe heart disease or pulmonary condition that precluded them being in a prone position for 40 minutes did not undergo breast MR. And the results of preoperative blood tests, chest $\mathrm{X}$-ray films and electrocardiograms were used to determine the pa-

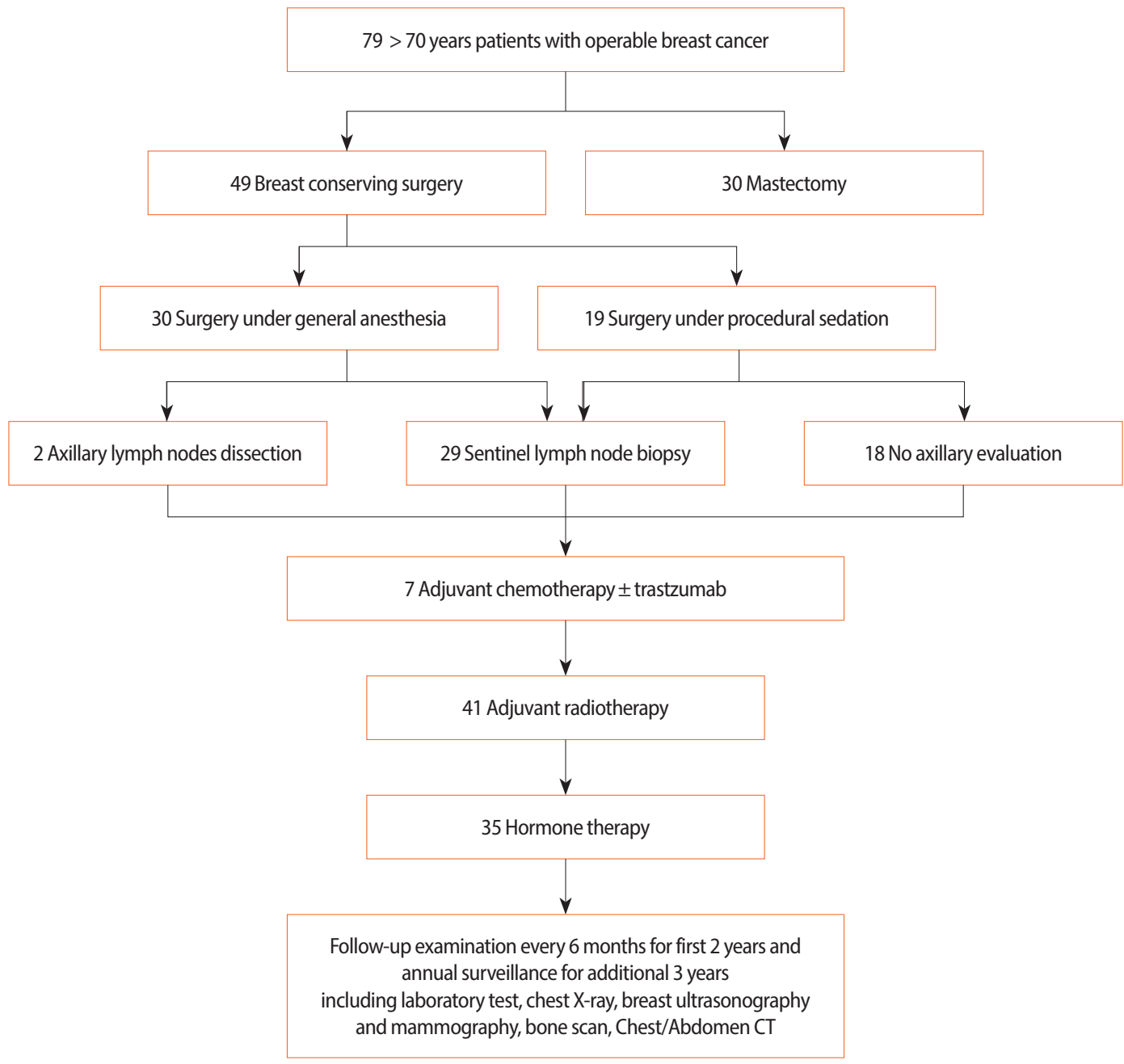

Figure 1. A flowchart showing management of breast cancer in elderly patients. 
tients' ASA physical status.

Informed consent for surgery and anesthesia was obtained from all patient and their caregivers by surgeons or anesthesiologists who explained the predicted risk of postoperative complications. A surgery under procedural sedation was decided for the patients and their family who refused general anesthesia because of high risk of postoperative morbidity or mortality. Among them, only one case was performed an axillary evaluation as sentinel lymph node biopsy.

General anesthesia was performed according to our institution's standards as either a balanced (BAL) or totally intravenous anesthetic technique using target controlled infusion (TCI). Patients were monitored throughout the procedure by measurement of $\mathrm{BP}$, heart rate, peripheral oxygen saturation, electrocardiogram, bispectral index (BIS), end tidal desflurane, and end tidal $\mathrm{CO}_{2}$. In the patients undergoing TCI, anesthesia was induced with continuous propofol and remifentanil infusion (Orchestra ${ }^{\circledR}$ with Base Primea; Fresenius Kabi, France) to reach 3-4 $\mu \mathrm{g} \mathrm{mL}^{-1}$ and 2-4 $\mathrm{ng} \mathrm{mL}^{-1}$ of target effect-site concentration $(\mathrm{Ce})$. In those undergoing BAL, anesthesia was induced with propofol $2 \mathrm{mg} \mathrm{kg}^{-1}$ and continuous remifentanil infusion, using TCI to reach $2-4 \mathrm{ng} \mathrm{mL}^{-1}$ of Ce. All patients were intubated and ventilation was adjusted to maintain an end tidal $\mathrm{CO}_{2}$ between 30 and 35 $\mathrm{mmHg}$ throughout the surgery. BIS values were used to guide administration of propofol and desflurane. The target range of BIS during maintenance was 40-50. Mean arterial pressure and HR were used to guide administration of remifentanil, the aim being to maintain them within $20 \%$ of preoperative values. At the end of surgery, neuromuscular blockade was reversed with pyridostigmine and glycopyrrolate $(0.2 \mathrm{mg} / \mathrm{kg}$ and $0.008 \mathrm{mg} / \mathrm{kg}$, respectively).

Procedural sedation was performed with intravenous injection of a sedative (Midazolam ${ }^{\circledR}$ Bukwang Pharm, Seoul, Korea) and analgesic agent (Pethidine ${ }^{\circledR}$ Jeil Pharmaceutical Co. Ltd., Daegu, Korea) and monitored by surgeons themselves. Patient was placed in the supine position with both arms abducted and a peripheral capillary oxygen saturation $\left(\mathrm{SpO}_{2}\right)$ was measured with a pulse oximeter during surgery. The intravenous agents were administered as 5-mg of Midazolam ${ }^{\circledR}$ mixed in 100-mL of normal saline, started at the time of breast draping in $60 \mathrm{gtt} / \mathrm{minute}$ and $50-\mathrm{mg}$ of Pethidine ${ }^{\circledR}$ mixed in $100-\mathrm{mL}$ of normal saline, started at the time of surgical incision in $12 \mathrm{gtt} /$ minute. Before the surgical incision was initiated, 2\%, 5-mL of Lidocaine ${ }^{\circledR}$ was injected on subcutaneous layer. When the patient feel operative site pain, the $2 \%$ of Lidocaine was more injected or IV rate of Pethidine ${ }^{\circledR}$ was raised.

Conventional breast-conserving surgery or mastectomy was performed, the surgical margins being evaluated after breast-conserving surgery by intraoperative frozen section. When a surgical margin was found to be positive, additional resection was performed until the surgical margin was confirmed as tumor-free. Sentinel lymph node biopsy (SLNB) or axillary lymph nodes dissection (ALND) was performed according to axillary lymph node status.

Although the main breast lesion was widely removed to achieve safe margins, surgical margins were not evaluated by frozen section in patients undergoing procedural sedation. Additionally, SLNB was rarely performed in the procedural sedation group because of pain and time limitations. Postoperative adjuvant treatments were administered according to tumor stage, hormone receptor status, and HER2 gene positivity.

Various clinicopathologic variables including age, body mass index

Table 1. Clinical characteristics of 79 patients with breast cancer aged $>70$ years

\begin{tabular}{lc}
\hline Characteristic & No. $(\%)$ \\
\hline Age $(\mathrm{yr})^{*}$ & $75.6 \pm 4.11$ \\
Body mass index $\left(\mathrm{kg} / \mathrm{m}^{2}\right)^{*}$ & $23.1 \pm 2.79$ \\
Comorbidity & \\
Hypertension & $47(59.5)$ \\
Diabetes mellitus & $35(44.3)$ \\
Heart disease & $16(20.3)$ \\
Asthma & $4(5.1)$ \\
Neuro-psychogenic disorder & $11(13.9)$ \\
Other malignancy & $7(8.9)$ \\
American Society of Anesthesiologists (ASA) physical status & \\
II & $58(73.4)$ \\
III & $21(26.6)$ \\
Bilaterality & $7(8.9)$ \\
Location of tumor & \\
Right & $45(57.0)$ \\
Left & $34(43.0)$ \\
Type of breast surgery & \\
Mastectomy & $30(38.0)$ \\
Breast-conserving surgery & $49(62.0)$ \\
Type of anesthesia & \\
General anesthesia & $60(75.9)$ \\
Procedural sedation & $19(24.1)$ \\
Hospital stay (day)* & $5.7 \pm 4.7$ \\
Duration of follow up (month)* & $36.6 \pm 6.04$ \\
Local recurrence & $1(1.3)$ \\
\hline
\end{tabular}

*Mean \pm SD. 
(BMI), underlying disease, length of hospital stay, duration of fasting, ASA physical status, bilaterality, tumor location, type of surgery and anesthesia, duration of follow up, and oncologic results were analyzed. Pain was assessed immediately postoperatively on a visual analog scale (VAS) [14]. All variables were compared between the general anesthesia and procedural sedation subgroups of the breast-conserving surgery group. The statistical significance of differences in variables between groups was performed using the $\chi^{2}$ or Student's t-test for categorical and continuous variables, respectively.

\section{RESULTS}

The overall mean age was 75.6 years $( \pm \mathrm{SD}, 4.11)$ and mean BMI was $23.1 \mathrm{~kg} / \mathrm{m}^{2}$ ( $\pm \mathrm{SD}, 2.79$ ). Among them. 47 patients (59.5\%) had hypertension, 35 (44.3\%) patients had diabetes mellitus, 16 (20.3\%) pa-

Table 2. Comparison of clinical and treatment-related variables in patients who had undergone breast-conserving surgery according to type of anesthesia

\begin{tabular}{|c|c|c|c|}
\hline Variables & $\begin{array}{c}\text { General } \\
\text { anesthesia } \\
(\mathrm{n}=30) \\
\text { No. }(\%)\end{array}$ & $\begin{array}{c}\text { Procedural } \\
\text { sedation } \\
(n=19) \\
\text { No. }(\%)\end{array}$ & $p$-value \\
\hline Age $(y r)^{*}$ & $74.0 \pm 1.90$ & $81.3 \pm 5.71$ & 0.014 \\
\hline Body mass index $\left(\mathrm{kg} / \mathrm{m}^{2}\right)^{*}$ & $23.1 \pm 3.42$ & $24.3 \pm 3.15$ & 0.256 \\
\hline $\begin{array}{l}\text { American Society of Anesthesiologists } \\
\text { (ASA) physical status }\end{array}$ & & & 0.035 \\
\hline ॥ & $23(76.7)$ & $5(26.3)$ & \\
\hline III & $7(23.3)$ & $14(73.7)$ & \\
\hline Hospital stay (day)* & $3.1 \pm 1.41$ & $1.3 \pm 0.76$ & $<0.001$ \\
\hline Mean operation time (minute)* & $72.5 \pm 10.6$ & $25.3 \pm 16.8$ & 0.024 \\
\hline Mean pain score* & $7.5 \pm 1.8$ & $5.8 \pm 2.9$ & 0.076 \\
\hline Mean fasting time (minute) ${ }^{*}$ & $992.3 \pm 64.5$ & $495.7 \pm 84.1$ & 0.013 \\
\hline Bilaterality & $5(16.7)$ & $2(10.5)$ & 0.701 \\
\hline Location & & & 0.719 \\
\hline Right & $12(40.0)$ & $9(47.4)$ & \\
\hline Left & $18(60.0)$ & $10(52.6)$ & \\
\hline Evaluation for axillary lymph nodes & & & $<0.001$ \\
\hline None & 0 & $18(94.7)$ & \\
\hline Sentinel lymph node biopsy & $28(93.3)$ & $1(5.3)$ & \\
\hline Axillary lymph node dissection & $2(6.7)$ & 0 & \\
\hline Weight of removed breast tissue (g)* & $46.7 \pm 44.87$ & $27.2 \pm 5.45$ & 0.098 \\
\hline $\begin{array}{l}\text { Postoperative complication, } \\
\text { hematoma }\end{array}$ & $1(3.3)$ & $1(5.3)$ & 0.404 \\
\hline Adjuvant chemotherapy & $4(13.3)$ & $3(15.8)$ & 0.839 \\
\hline Adjuvant radiotherapy & $24(80.0)$ & $17(89.5)$ & 0.641 \\
\hline Adjuvant target therapy & $3(10.0)$ & $1(5.3)$ & 0.693 \\
\hline Adjuvant hormone therapy & $23(76.7)$ & $12(63.2)$ & 0.784 \\
\hline
\end{tabular}

*Mean \pm SD. tients had various forms of heart disease, and $4(5.1 \%)$ patients had been diagnosed asthma.

As to ASA physical status, 58 patients (73.4\%) were classified as Class II and 21 (26.6\%) as Class III. Depending on tumor size, 30 patients (38.0\%) had undergone mastectomy under general anesthesia and the remaining 49 had undergone breast-conserving surgery under general (30 patients; 38.0\%) or local (19 patients; $24.1 \%$ ) anesthesia. The mean duration of follow up was 36.6 months ( \pm SD, 6.04). One patient had developed a local recurrence in the axillary area (Table 1).

The mean age was significantly younger in general anesthesia group ( $p=0.014)$ and more patients had grade III ASA physical status in procedural sedation group $(p=0.035)$. The mean operation time and hospital stay shorter in the procedural sedation group $(p=0.024$, $p<0.001)$. Only one patient in the procedural sedation group underwent evaluation of axillary nodes. Pain scores tended to be higher in the general anesthesia group; however, mean pain scores immediately

Table 3. Comparison of disease-related variables in patients who had undergone breast-conserving surgery according to type of anesthesia

\begin{tabular}{|c|c|c|c|}
\hline Variables & $\begin{array}{c}\text { General } \\
\text { anesthesia } \\
(\mathrm{n}=30) \\
\text { No. }(\%)\end{array}$ & $\begin{array}{c}\text { Procedural } \\
\text { sedation } \\
(n=19) \\
\text { No. }(\%)\end{array}$ & $p$-value \\
\hline Type of tumor & & & 0.312 \\
\hline Ductal carcinoma in situ & $3(10.0)$ & $1(5.3)$ & \\
\hline Invasive ductal carcinoma & $22(73.4)$ & $12(63.2)$ & \\
\hline Mucinous cancer & $4(13.3)$ & $2(10.5)$ & \\
\hline Other & $1(3.3)$ & $4(21)$ & \\
\hline Tumor grade & & & 0.152 \\
\hline 1 & $9(30.0)$ & $6(31.6)$ & \\
\hline 2 & $16(53.3)$ & $9(47.4)$ & \\
\hline 3 & $2(6.7)$ & $3(15.8)$ & \\
\hline Clinical tumor size $(\mathrm{cm})^{*}$ & $1.9 \pm 1.01$ & $2.1 \pm 0.65$ & 0.540 \\
\hline Pathologic tumor size $(\mathrm{cm})^{*}$ & $1.8 \pm 0.70$ & $1.9 \pm 0.70$ & 0.483 \\
\hline Clinical N stage & & & 0.555 \\
\hline No & $26(86.7)$ & $18(94.7)$ & \\
\hline N1 & $3(10.0)$ & $1(5.3)$ & \\
\hline N2 & $1(3.3)$ & 0 & \\
\hline Margin status & & & 0.464 \\
\hline Negative & $28(93.3)$ & $18(94.7)$ & \\
\hline Positive & $2(6.7)$ & $1(5.3)$ & \\
\hline Estrogen receptor positive & $21(70.0)$ & $13(68.4)$ & 0.131 \\
\hline Progesterone receptor positive & $18(60.0)$ & $11(57.9)$ & 0.093 \\
\hline HER2 gene amplification & $5(16.7)$ & $3(15.8)$ & 0.415 \\
\hline Triple negative breast cancer & $3(10.0)$ & $2(10.5)$ & 0.068 \\
\hline Duration of follow up (month)* & $36.2 \pm 5.82$ & $37.8 \pm 7.51$ & 0.615 \\
\hline Local recurrence & $1(3.3)$ & 0 & 0.067 \\
\hline
\end{tabular}

*Mean \pm SD. 
postoperatively did not differ significantly between the two groups $(p=0.076)$. Even if the axillary evaluation was not performed in procedural sedation group except one case, three patients received adjuvant chemotherapy due to triple negative breast cancer $(n=2)$ and HER2-positive breast cancer ( $\mathrm{n}=1$ ) (Table 2).

There was only one case of local recurrence in patient who was received breast conserving surgery with sentinel lymph node biopsy under general anesthesia. However, any metastasis or death was not occurred during follow-up period. And there was no significant difference of pathologic characteristics between two groups and the oncologic results, also, did not show statistical significance between two groups (Table 3).

\section{DISCUSSION}

Geriatric patients differ from younger patients in that they are more likely to have multiple comorbidities and their vital organs are less robust [15]. Breast cancer usually grows more slowly in older than younger patients and has a better prognosis and higher rate of hormone receptor positivity [16-19]. Although all patients with breast cancer, including older patients, should be treated according to standard treatment protocols, older patients are frequently under-evaluated or under-treated because of comorbidities, insufficient socio-economic support, or the decisions of their caregivers $[6,20]$.

Surgery is the most important modality for treating breast cancer disease and achieving optimal outcomes and is generally supported by adjuvant treatments [21-23]. These general principles hold true for elderly. Surgery for breast cancer is generally performed under general anesthesia and comprises removal of the primary lesion and evaluation of axillary lymph node status. There are several reasons for performing breast cancer surgery, including breast-conserving surgery, under general anesthesia. First, definitive pathologic evaluation of intraoperative margins takes quite a long time. In the case of breast-conserving surgery, the need for any additional excision can be determined by examination of frozen sections. Second, surgery in the axillary area is relatively painful because there are many sensory nerves in this region. Additionally, ALND is more dangerous procedure than breast surgery because it involves exposure of major vessels and therefore requires a meticulous procedure.

When older patients with breast cancer are considered at high risk of perioperative complications after general anesthesia, surgeons must decide whether to give forego surgery or choose another type of anesthesia. Important considerations include the following. A meta-analysis has shown that the results of hormone treatment alone without surgery are inferior to those achieved by surgery with or without hormone treatment [24]. Additionally, because reducing tumor burden is important in treatment of breast cancer, intensive treatment including surgery and chemotherapy is optimal even in older patients.

Elderly patients with breast cancer are frequently received under-treatment for their disease. However, if a tumor burden has been decreased after removal of primary breast cancer, even if the axillary dissection, adjuvant radiotherapy or chemotherapy is omitted, the oncologic outcome was not inferior to conventional treatment of breast cancer [25]. Similarly in the present study, although axillary lymph node status was not assessed in the former, the oncologic results did not differ significantly between the general anesthesia and procedural sedation groups during follow-up. However, the mean hospital stay and fasting time were shorter in the procedural sedation group, which may have assisted postoperative recovery. Additionally, the mean pain score immediately postoperatively was lower in the procedural sedation group. However, because these patients did not undergo axillary surgery, comparison of pain scores is not valid.

Surgical removal of breast cancer under procedural sedation may have advantages over not performing any surgery in patients for whom general anesthesia is assessed as too risky. First, excision decreases tumor burden, enabling maximal therapeutic effects from adjuvant treatment, especially hormone treatment. Second, excision minimizes progression to inflammatory or metastatic breast cancer, resulting in a better quality of life. Third, excision enables more precise characterization of tumors, which is helpful in deciding on adjuvant treatment. Fourth, removal of the tumor likely reduces tumor-related fear and anxiety.

There is little published evidence that procedural sedation is superior to general anesthesia. Sedatives and analgesics should be used with caution in older patients because changes in their body composition and pharmacokinetics can affect the absorption, distribution, and elimination of such agents [26,27]. Moreover, shock or acute heart issues can occur when older persons experience severe pain or stimulation during surgery under procedural sedation. Thus, surgery under general anesthesia may be safer because this prevents any pain or fear 
intraoperatively.

However, procedural sedation bypasses potential life-threatening complications of general anesthesia. In addition, the recommended perioperative fasting time is shorter for procedural sedation, which minimizes any exacerbations of catabolic states and enables better nutritional support, thus facilitating recovery [28].

There are several limitations. First, the population was small and follow up period was not long. Therefore, even if the authors performed multivariate analysis as well, we could not satisfactory statistical results. Further study would be necessary to analyze more accurate oncologic outcomes for breast cancer. Second, in most case, the sentinel lymph node biopsy was not done which could affect to analysis. In addition, since the surgery under procedural sedation was performed for the elderly patients who had relatively early breast cancer, this could be a bias in analyzing. However, this study is the first study of oncologic data in comparing anesthetic method for elderly patients with breast cancer. And this study shows very optimistic aspect of surgical role in those patients.

In conclusion, a breast surgery under procedural sedation is a safe and effective means of reducing tumor burden in older patients with breast cancer who are considered at unacceptable risk of life-threatening perioperative complications after general anesthesia on the basis of ASA physical status. And the oncologic results of breast conserving surgery under procedural sedation may be not inferior to breast conserving surgery under general anesthesia.

\section{CONFLICT OF INTEREST}

The authors declare that they have no competing interests.

\section{REFERENCES}

1. Raftery AE, Chunn JL, Gerland P, Sevčíková H. Bayesian probabilistic projections of life expectancy for all countries. Demography 2013;50:777-801.

2. Muss HB. Coming of age: breast cancer in seniors. Oncologist 2010;15(Suppl5):57-65.

3. Schairer C, Mink PJ, Carroll L, Devesa SS. Probabilities of death from breast cancer and other causes among female breast cancer patients. J Natl Cancer Inst 2004;96:1311-21.
4. Chung M, Chang HR, Bland KI, Wanebo HJ. Younger women with breast carcinoma have a poorer prognosis than older women. Cancer 1996;77:97-103.

5. Pierga JY, Girre V, Laurence V, Asselain B, Diéras V, Jouve M, et al. Characteristics and outcome of 1755 operable breast cancers in women over 70 years of age. Breast 2004;13:369-75.

6. Tesarova P. Breast cancer in the elderly-Should it be treated differently? Rep Pract Oncol Radiother 2012;18:26-33.

7. Swaminathan V, Spiliopoulos MK, Audisio RA. Choices in surgery for older women with breast cancer. Breast Care (Basel) 2012;7:44551.

8. Audisio RA, Bozzetti F, Gennari R, Jaklitsch MT, Koperna T, Longo $\mathrm{WE}$, et al. The surgical management of elderly cancer patients; recommendations of the SIOG surgical task force. Eur J Cancer 2004;40:926-38.

9. Spazzapan S, Crivellari D, Bedard P, Lombardi D, Miolo G, Scalone $\mathrm{S}$, et al. Therapeutic management of breast cancer in the elderly. Expert Opin Pharmacother 2011;12:945-60.

10. Singletary SE, Shallenberger R, Guinee VF. Breast cancer in the elderly. Ann Surg 1993;218:667-71.

11. Marian AA, Bayman EO, Gillett A, Hadder B, Todd MM. The influence of the type and design of the anesthesia record on ASA physical status scores in surgical patients: paper records vs. electronic anesthesia records. BMC Med Inform Decis Mak 2016;16:29.

12. Fennessy M, Bates T, MacRae K, Riley D, Houghton J, Baum M. Late follow-up of a randomized trial of surgery plus tamoxifen versus tamoxifen alone in women aged over 70 years with operable breast cancer. Br J Surg 2004;91:699-704.

13. Sacchini VS, Pluchinotta AM, Vindigni V. The role of surgery on breast cancer. In: Pluchinotta AM, editors. The Outpatient Breast Clinic, Aiming at Best Practice, New York: Springer; 2015. p. 35390.

14. Hawker GA, Mian S, Kendzerska T, French M. Measures of adult pain: Visual Analog Scale for Pain (VAS Pain), Numeric Rating Scale for Pain (NRS Pain), McGill Pain Questionnaire (MPQ), Short-Form McGill Pain Questionnaire (SF-MPQ), Chronic Pain Grade Scale (CPGS), Short Form-36 Bodily Pain Scale (SF-36 BPS), and Measure of Intermittent and Constant Osteoarthritis Pain (ICOAP). Arthritis Care Res (Hoboken) 2011;63(Suppl 11):S24052. 
15. Finucane TE. How is geriatrics different from general internal medicine? Geriatr Gerontol Int 2004;4:259-61.

16. Samain E, Schauvliège F, Deval B, Marty J. Anesthesia for breast cancer surgery in the elderly. Crit Rev Oncol Hematol 2003;46:11520

17. Semiglazov VF, Moiseenko VM. Does breast cancer grow slower in elderly patients? Vopr Onkol 1994;40:298-302.

18. Clark GM. The biology of breast cancer in older women. J Gerontol 1992;47:19-23.

19. Bergman L, Dekker G, van Leeuwen FE, Huisman SI, van Dam FS, van Dongen JA. The effect of age on treatment choice and survival in elderly breast cancer patients. Cancer 1991;67:2227-34.

20. Gajdos C, Tartter PI, Bleiweiss IJ, Lopchinsky RA, Bernstein JL. The consequence of undertreating breast cancer in the elderly. J Am Coll Surg 2001;192:698-707.

21. Halsted WS. The results of operations for the cure of cancer of the breast performed at the Johns Hopkins Hospital from June 1889 to January 1894. Ann Surg 1894;320:497-555.

22. Sabel MS, Diehl KM, Chang AE. Principles of Surgical Therapy in Oncology. In: Chang AE, Ganz PA, Hayes DF, Kinsella T, Pass HI,
Schiller JH, Stone RM, Atrecher V, editors. Oncology, An Evidence-Based Approach, New York: Springer; 2006. p. 58-72.

23. Mislang AR, Cheung KL, Hamaker ME, Kunkler I, Markopoulos C, Orecchia R, et al. Controversial issues in the management of older adults with early breast cancer. J Geriatr Oncol 2017:8:397-402.

24. Hind D, Wyld L, Beverley CB, Reed MW. Surgery versus primary endocrine therapy for operable primary breast cancer in elderly women (70 years plus). Cochrane Database Syst Rev 2006;1: CD004272.

25. Gajdos C, Tartter PI, Bleiweiss IJ, Lopchinsky RA, Bernstein JL. The consequence of undertreating breast cancer in the elderly. J Am Coll Surg 2001;192:698-707.

26. Kwak KH, Park SS. Regional anesthetic management of elderly patients. J Korean Med Assoc 2017;60:377-83.

27. Simon MJ, Veering BT. Factors affecting the pharmacokinetics and neural block characteristics after epidural administration of local anaesthetics. Eur J Pain Suppl 2010;4:209-18.

28. Liu M, Yang J, Yu X, Huang X, Vaidya S, Huang F, et al. The role of perioperative oral nutritional supplementation in elderly patients after hip surgery. Clin Interv Aging 2015;10:849-58. 